\title{
Mycophenolate Mofetil in severe or methotrexate refractory localized scleroderma
}

\author{
G Martini*1, F Falcini² ${ }^{2}$ H Girschick ${ }^{3}$, D Goldsmidt ${ }^{4}$ and F Zulian ${ }^{5}$
}

Address: ${ }^{1}$ Department of Paediatrics, Padova, Italy, ${ }^{2}$ Internal Medicine, Transition Unit, Florence, Italy, ${ }^{3}$ Immunology and Rheumatology, Univ. Kinderklinik, Wuerzburg, Germany, ${ }^{4}$ St. Christopher's Hospital for Children, Drexel, USA and ${ }^{5}$ Department of Paediatrics, Padova, Italy

* Corresponding author

from I5th Paediatric Rheumatology European Society (PreS) Congress

London, UK. 14-17 September 2008

Published: 15 September 2008

Pediatric Rheumatology 2008, 6(Suppl I):P229 doi:I0.II86/I546-0096-6-SI-P229

This abstract is available from: http://www.ped-rheum.com/content/6/SI/P229

(c) 2008 Martini et al; licensee BioMed Central Ltd.

Juvenile Localized Scleroderma (JLS), is characterised by presence of areas of skin thickening, which is relatively benign, but if deeper tissues such as muscle and bone are involved severe deformities may develop. Mycophenolate Mofetil (MMF) is increasingly utilised both for treatment of systemic sclerosis and immune-mediated skin diseases such as psoriasis, graft-versus-host and lichen planus. Our aim was to evaluate efficacy and safety of MMF in the treatment of JLS. Seven patients entered the study ( $3 \mathrm{M}, 4$ F). The JLS clinical subtypes were Pansclerotic morphea (2 pts), Generalized Morphea (1), En coup de Sabre (ECDS) (1), Mixed (ECDS/Linear) (3), The age at onset of the disease was 7.5 yrs (range $3-16.9$ ) and the disease duration at diagnosis was 1.9 years (range 3 months -4 years). Previous treatments before starting MMF were oral steroids in 6 pts, IV steroids in 5, MTX in 5, while the patient with ECDS received no treatment. MMF was started because of steroids side effects in one patient and MTX resistance in 5. In ECDS MMF was chosen because of concomitant cerebral vasculitis. All treated patients presented clinical improvement which allowed withdrawal of steroids. Over the follow-up of 27 months (range 6-36 months) only mild abdominal discomfort in one patient was reported. In conclusion MMF seems to be effective in severe or MTXrefractory JLS and is generally well tolerated. Further controlled studies are necessary to confirm these data. 